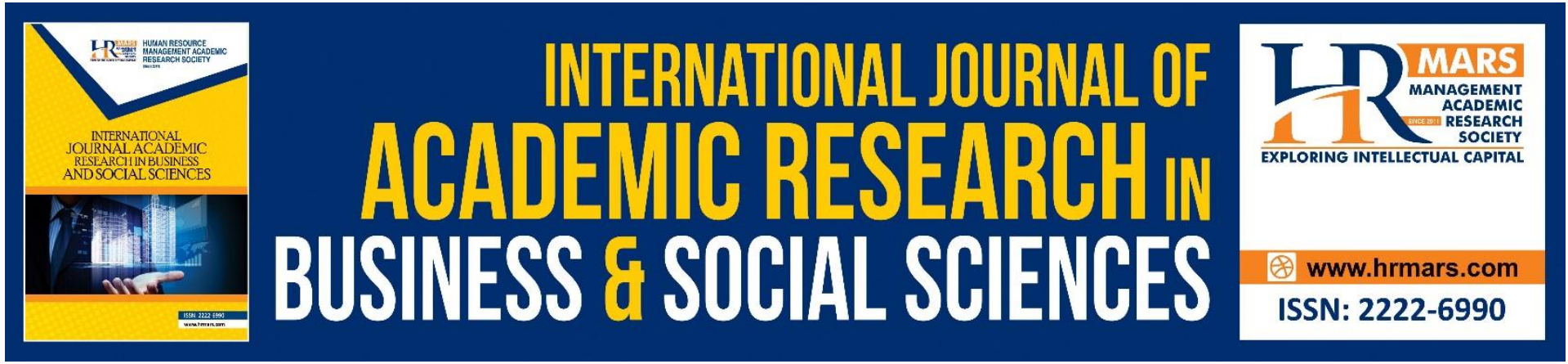

\title{
A Multimodal Analysis of Cartoon in Jordan
}

\author{
Isra Mahmoud ALjrah, Rafeah Legino, Rusmadiah Anwar
}

To Link this Article: http://dx.doi.org/10.6007/IJARBSS/v11-i9/11037

DOI:10.6007/IJARBSS/v11-i9/11037

Received: 09 July 2021, Revised: 04 August 2021, Accepted: 30 August 2021

Published Online: 10 September 2021

In-Text Citation: (ALjrah et al., 2021)

To Cite this Article: ALjrah, I. M., Legino, R., \& Anwar, R. (2021). A Multimodal Analysis of Cartoon in Jordan. International Journal of Academic Research in Business and Social Sciences, 11(9), 521-546.

Copyright: (C) 2021 The Author(s)

Published by Human Resource Management Academic Research Society (www.hrmars.com)

This article is published under the Creative Commons Attribution (CC BY 4.0) license. Anyone may reproduce, distribute, translate and create derivative works of this article (for both commercial and non-commercial purposes), subject to full attribution to the original publication and authors. The full terms of this license may be seen

at: http://creativecommons.org/licences/by/4.0/legalcode

Vol. 11, No. 9, 2021, Pg. $535-546$

http://hrmars.com/index.php/pages/detail/IJARBSS

JOURNAL HOMEPAGE

Full Terms \& Conditions of access and use can be found at http://hrmars.com/index.php/pages/detail/publication-ethics 


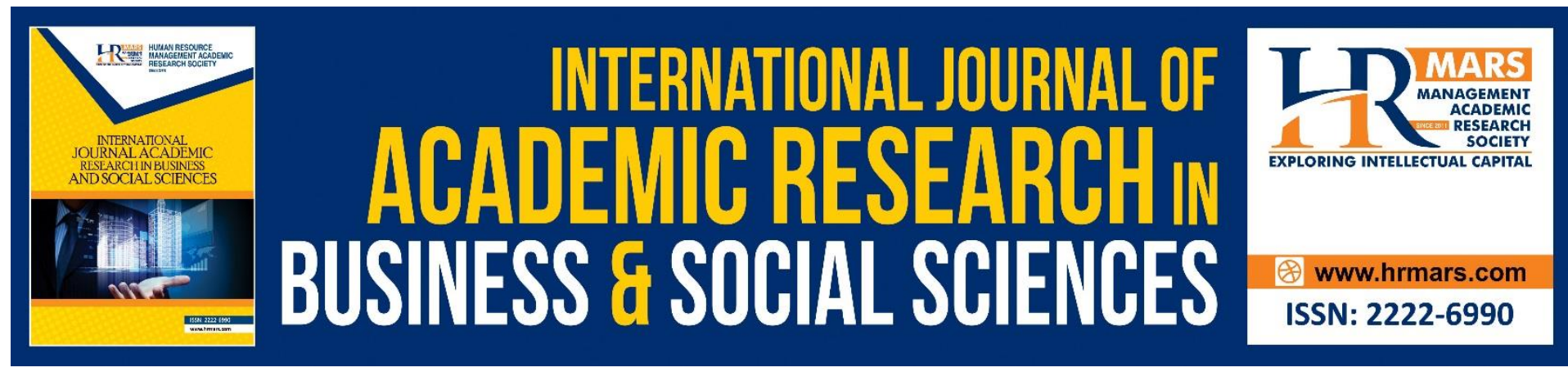

\title{
A Multimodal Analysis of Cartoon in Jordan
}

\author{
Isra Mahmoud ALjrah, Rafeah Legino, Rusmadiah Anwar
}

Faculty of Art \& Design, Universiti Teknologi MARA 40450 Shah Alam Selangor Malaysia

Email: israhassan_2010@yahoo.com,rafeahl@uitm.edu.my, rusma9252@uitm.edu.my

\begin{abstract}
A cartoon is a kind of two-dimensional painting which can also be animated. The definition has changed in recent years, and these days the utilisation of cartoons is referred to as ordinarily non-realistic or could be the semi-realistic artistic style of drawing or painting, a picture or an arrangement of images expected for parody or humour, or could be a movie that depends on a succession of paintings for its liveliness. Any artist who makes cartoons is called a cartoonist. In Jordan, cartoons are regarded as political commentary; they are seen as an expression of some political points that should be noted, but many of the cartoons are not linked to the Jordanian cultural discourse and are not analysed due to the lack of previous studies which have been done in the Middle East. Also, there is a need to highlight the importance of the interaction of semantic and linguistic elements in Jordanian media to determine the more common and suitable pattern. Therefore, this study aims to be an essential reference for Jordanian cartoonists and researchers to develop the cartoon industry in Jordan and increase its influence and influence in society, as it is in developed societies. Through a review of previous studies on the analysis of social discourse and presented studies on the analysis of multimedia in cardboard in developed countries, the evaluation of the importance played by cartoons in various areas will explain the gap in previous studies in the Middle East and particularly in Jordan. The potential future study, the data analysis through modality, could be a possible topic for future research to explore interpersonal meaning created between authors and viewers and the effect of social media on the multimodal analysis of cartoons in Jordan.
\end{abstract}

Keywords: Analysis, Cartoon, Discourse, Social, Multimodal, Jordan

\section{Introduction}

Cartoons are rich sources of information. Being practical specialised tools, Cartoons are vital to the aggregate instruction of each individual from the general public they depict. In the western world, the level of flexibility and respecting rights has no restrictions and boundaries, in the two sides: social and political, so any of these studies around this issue will be great, and the result is linked to the social discourse in the western society, so the cartoon themes are relevant to the address in western culture, and the cartoon models are analysed based on the theme used (Gill \& Singh, 2015). While the general public and legislative issues are so delicate to exposure and feedback, Cartoon is utilised as a non-coordinate route for disclosure in the Middle East. New ages in the Middle East are witnessed. In Jordan, they began to use the latest innovations of strike back Jordan (Al-Mahadin, 2003). 
In Jordan, Cartoon is regarded as a political comment; they are seen as an expression making some political points that should be noted, but many of the cartoons are not linked to the Jordanian culture discourse. They are not analysed due to the lack of theme understanding and studies, so by having a closer look at this issue, we can realise that there was a gap in the previous studies done in the middle east. Therefore, this study will cover the gap between the earlier studies and the need for more investigation on how the cartoon social discourse in the Middle East reflects the society in the Middle East and Jordan by linking it with the Jordanian social address in Jordan. Also, there is a need to highlight the importance of the interaction of semantic and linguistic elements in Jordanian Media to determine the more common and suitable pattern.

Images present a fascinating and challenging field of interest. There is no single definition of images, though different meanings and usage can overlap. According to Ludwig Wittgenstein, to make sense of a term such as an image, one must perceive a complex network of relations between the different meanings. Taking Wittgenstein's point of view, there cannot be absolute clarity in terms of a philosophical concept of the image, nor a designated set of tools to guide research in advance. The image remains a focal point in visual culture studies which are broader than image studies. David Morgan's definition of visual culture makes the basis of this article an analytical approach. Visual culture is the act of seeing and attendant intellectual, emotional, and perceptual sensibilities to build, maintain, or transform the world in which people live. The study of visual culture is the analysis and interpretation of images and the way of seeing (gazes) that configure the agents. The objective is to be an essential reference for the Jordanian cartoonists and researchers to develop the cartoon industry in Jordan and increase its influence and influence in society as it is in developed societies. Through a review of previous studies on the analysis of social discourse and presented studies on the analysis of multimedia in cardboard in developed countries and review the importance played by the cartoon in various areas will explain the gap in previous studies in the Middle East and particularly in Jordan.

\section{Critical Discourse Analysis}

Dialect is proof of the amazingness of man on the planet rather than different animalshuman impacts to other people and creatures which do not express their sentiments, purposely and reliably. Verbal highlights of dialect interest the members to convey, and the dialect used in correspondence is the discourse, where "discourse is a dialect used over a sentence" (Stubbs, 1983, p.1). The investigation of discourse is, fundamentally, the examination of dialect being used (Mary-Totry, 2015). Essential discourse investigation (CDA), notwithstanding, is a type of discourse diagnostic examination that dominatingly investigates the way social power is mishandled, strength and disparity are established, duplicated and opposed by content and discourse in the social and political setting" (Van-Dijk, 1993a). AlAli's cartoons influenced millions of people throughout the Arab world's His cartoons were not intended to entertain the readers but instead always conveyed political messages. In addition to expressing his personal views, they were sarcastic and daring reflections of the feelings of the Palestinian refugees. The loss of Palestine was the main inspiration for his cartoons. Therefore, he dedicated most of his comics to the suffering of his people, especially the poor living in the refugee camps. His work was also dedicated to the oppressed people of the Arab world and oppressed people worldwide. Although most of his cartoons were very pessimistic, some were full of hope, dreams, and aspirations for a better life for the Arab people and the Palestinians. Al-Ali addressed taboo issues while avoiding the strict censorship 
imposed on Arab newspapers. His cartoons were simple, straightforward to understand and were often published next to editorials with political messages. The comics spoke to and about ordinary people regarding their political or economic or even mimic issues. His readers waited eagerly to see his drawing on the last page (which became their front page) of many Arab dailies in Lebanon, Kuwait, Tunisia, Abu Dhabi, Egypt, London and Paris.

On the other hand, many Arab countries prohibited him from entering and banned his cartoons from their local newspapers (Mandell, 2016). The straightforward idea of essential discourse examination (CDA) tries to handle, reveal and repulse social separation.) Handala's figure can be seen at festivals and parades alongside other Palestinian iconographic symbols, 57 such as the map of villages destroyed during the Nakba. Handala has also been adopted as the formal icon of UNESCO's freedom organisation. A 2012 film about Arab life was greatly admired throughout the Arab world (Arjan, 2010). In 2007 a documentary film called The Icon was made about his life, and in 2008 he was a dominant figure at the 60th commemoration of Al-Nakba. Many exhibitions of his work have been shown worldwide under the title "Shooting the Witness." They have advanced methodologies and speculations for investigating multimodal discourse, which depend on Halliday's (2004) foundational utilitarian phonetics. Halliday's (2014) meta work is considered the essential precept of fundamental practical hypothesis to break down multimodal discourse. It gives a brought together stage to offer speculations that show how unique semiotic assets cooperate and build the planned importance (O'Halloran, 2008).

Gunther Kress and Theo van Leeuwen (Mary-Totry,2013) are the occasions of principle researchers who did ponder towards multimodality. Pictures and visual examples of a different scope of writings, including ads, were the focal point of Kress and Van-Leeuwen's $(1996,2006)$ investigation following Halliday's (2004) fundamental practical approach. The message quickly, clearly and descriptively. Often these means have enabled the masses to see their social, economic and political reality in a new and critical light. Social, economic and political cartoons are a popular tool of expression in the media. Cartoons appear every day in the newspapers, often adjacent to the editorials.

In many cases, cartoons are more successful in demonstrating ideas and information, which are complex verbal explanations that require a significant investment of time by the writer and the reader. Comics attract attention and curiosity, can be read and understood quickly and can communicate subversive messages camouflaged as jokes that bring a smile to the reader's face. Cartoons become more effective and successful in countries with strict censorship and widespread illiteracy, among them many countries in the Arab world. Dialect is characterised by Eggins (2004) as relevant, useful, semantic and semiotic. She additionally pronounces that the most explained semiotic framework is dialect as in any communication; the conversationalists get associated with passing on precisely a message the crowd ought to know about and the correct decision of word. Etymological or visual assets alone aren't as imperative and successful as when they are as one with different assets in a necessary process (Nugroho, 2009). Christie (2005) contends that multimodality has been with us since individuals used to draw or paint on the divider to speak with each other.

Previous studies focused on critical discourse without relating it to the culture In the Middle East and considering the younger generation connected to social media technologies such as Facebook and Twitter. This study is more updated regarding the Middle Eastern and Jordanian culture and focused more on the contemporary Character Model in the Jordanian caricature. As Jordanian authorities increasingly relied on press gag orders in 2016 to prevent public reporting on sensitive issues. In 2016, authorities imposed gag orders on news stories 
such as a complaint by orphans against the Ministry of Social Development; a street assault on an Egyptian worker in Jordan; a security operation in the northern town of Irbid in March in which seven militants and one policeman were killed; an attack on a General Intelligence Directorate (GID) office north of Amman that led to four deaths; and the cases of Amjad Qourshah and Nahed Hattar. On August 29, Jordan's media commission prohibited local press outlets from publishing any news about the king or the royal family other than information circulated by the royal court. A legislative overhaul of the penal code was put to parliament in 2015, proposing to amend at least 180 articles of the 1960 code. At the time of writing, lawmakers had still to pass the reforms. For the first time, the draft amendments provided alternatives to imprisonment, such as community service.

\section{Multimodal in Cartoon}

The 'multimodality' term started from two weighty works of Kress and van Leeuwen, precisely 'Perusing Images' (1990) and 'Perusing Images: The Grammar of Visual Design' (1996). These two books were the base of multimodality look into (Kaltenbacher, 2004). The connection between different semiotic modes and their significance in the making of each semiotic method in the plan of semiotic items (e.g. magazines, leaflets) are the primary concern in the investigation of multimodality (Kress \& Van-Leeuwen, 2001). To be sure, in a multimodal content, verbal and visual components are united to pass on the message better. They featured that writings have dependably been multimodal as the composed content may not exist without spaces, shading and edges (Kaltenbacher, 2004). To be sure, reports with a few methods of discourse can be dissected through devices and strategies given by multimodality. The synchronous nearness of picture and sound through PC, web and TV makes multimodality conspicuous these days. Kress and Jewitt (2003) allude mode to the "regularised set of assets" which develop significance, for example, motion, discourse, picture and so forth. Having mindfulness about limitations in a culture and being familiar with the capacity of every mode would decide how every individual picks the methods to communicate something specific appropriately. It merits specifying that ways, by and large, go with and supplement each other.

Distinctive semiotic assets have been broken down utilising this hypothetical structure to recognise their significance in various discourses. Kress and Jewitt (2003) uncover that a mix of multiple modes would pass on the message, and all the included ways pass on the surmised importance since every method is in charge of one player in the message. This reality makes an all the more intense multimodal correspondence. It has been demonstrated that the watchers' mindfulness and comprehension would increase if at least two semiotic assets are combined. Each semiotic support has its part in building up content and incorporating them to create a more conceivable brought together range. Since the 1990s, distinct researchers (O'Toole, 1994; Lemke, 1998; Martinec, 1998; Van Leeuwen, 1999; O'Halloran, 2005; and Jones, 2006) investigated multimodal discourse examination (for example, activities, compositions, model and design) from Halliday's Systemic Functional point of view. Michael O'Toole (1994), Gunther Kress and Theo van Leeuwen (1996) stretched out this hypothesis to the understanding of the ways that visual modes understand. They are essential in social settings, and they were the pioneers of the exploration of multimodality.

Gunther Kress and Theo van Leeuwen $(1996,2006)$ are the cases of fundamental researchers who completed examinations on multimodality. Their system depends on the semantic connection inside semiotic assets with a specific goal to make between related frameworks and structures. They investigated metafunction and rank in artworks, design, 
showed craftsmanship and engineering. Kress and van Leeuwen (2001) alluded to Halliday's hypotheses of social semiotics as the purpose of take-off of social semiotic multimodal examination. Metafunction as the most persuasive piece of foundational utilitarian belief for multimodal discourse examination Halliday's (2004). Following Halliday's SFL hypothesis Kress and van Leeuwen give another social semiotics way to investigate the visual mode. Pictures and seeing examples of various writings, including promotions, was the focal point of Kress and van Leeuwen's (1996, 2006) examination following Halliday's (2004) fundamental utilitarian approach. Their approach featured that meta functions can separate a picture or a multimodal message during the time spent appreciating significance from the visual components introduced (Sørensen, 2011).

As it was said, social semiotics is the reason for the hypothesis of multimodality. Siegel (2006) claims that multimodality can be effectively comprehended by semiotics as "it offers a state of mind about significance and content that does not benefit dialect over other sign frameworks"(Siegel, 2006, p. 68). Van Leewen (2005, p.120) trusts that "pictures are additionally used to get things done to or for or with individuals: induce, educate, and clarify et cetera". Meurer (2010) contends that advances in innovation realise another important pattern that provokes semantics to react to this pattern by new types of proficiency, for example, multi-education, which incorporate both visual and phonetics components. In such a manner, educators themselves should know about the difficulties and troubles of perusing and understanding multimodal content. Consequently, to outfit understudies with the abilities essential to peruse multimodal messages thoroughly and basically, multi-proficiency comprises different methods of sign making and not simply dialect (Meurer, 2010).

It ought to be noted discoveries demonstrated that illustrated talk has a huge part in the forty-fourth presidential race of America and such factors as utilising film images, triumph in sports, bolster from vital people and associations on the planet, bolster from Democrats, bolster from mate, bolster from nature, bolster from the notable statue in American, bolster from individuals and being contrasted with contenders have influenced the triumph of Obama in the forty-fourth presidential decision of America.

\section{The Perspective of Multimodal in Asian Countries}

Malaysia is a multilingual and, in addition to the multicultural nation, which additionally grasps a significant number of races and non-natives from Western to Middle East nations. According to (Salveen Kaur Gill A/P Sakdev Singh 2015), he chose only spotlights on the main stories of the "Versatile World" magazines, which give promoting data relating to the new results of the well-known brands, for example, Samsung, Apple, and BlackBerry explored as far as a conceptual point of view to distinguish visual and etymological components utilising Kress and van Leeuwen's portrayal investigation and Halliday's Transitivity framework individually. Different viewpoints, for example, the format of the "Versatile World " magazine, can be broke down in other research to see how unique semiotic components are assembled to pass on a solid message.

About Hamid and Zafar (2017) Study "construction of south Asian politics: a study of Cartoons", The Critical discourse analysis (CDA) of the selected Asian Cartoons enhances the literal meanings of the text regarding power abuse and inequality. These Cartoons are installed to control governmental issues in the South Asian area. By a similar token, the examination ties the printed discourse with the mental design of the sketch artist that portrays his "intrinsic complex" as well as his uneasiness and sensitivity. The denotative and obvious articulations of discourse help expound the grimy picture of governmental energy 
issues. Furthermore, the data analysis through modality can be a potential topic for future research to explore interpersonal meaning created between authors and viewers.

\section{Term and Role of Cartoon}

The caricature is derived from the Italian word "caricature" or "carcase", which means "exaggerate", cartoons play a persuasive social and political party. Exaggerations can represent the sufferings of nationals by handling the issues of the general public, breaking down financial matters, and investigating problems. Political exaggerations can make help abused individuals by reprimanding existing conditions and unjustifiable political practices. Personifications can bargain strongly with social issues since they can escape restriction. It is conceivable to state that exaggerations can remedy issues quicker than composing words (Hafiz, 2006). By definition, (matty,2013;). Subsequently, "exaggeration" basically implies a "stacked picture" (Wikipedia, 2009). As Marshall McLuhan (Boeschoten, 2006) says, this is valid for cartoons as a medium. Exaggerations can be eulogistic and additionally fundamental. Much has been composed concerning why personifications are compelling from a stylish point of view (Gombrich, 1960; Ramachandran and Hirstein, 1999) and how personifications are made from a useful point of view (Gautier, 1985; Redman, 1984). However, in library and data science (LIS), personifications have been minimally considered from an exploration point of view.

It has not been wholly discoursed or bantered about to utilise exaggerations to recognise negative and feeble focuses. The consequences of this examination can enable custodians to accomplish a superior status and convey the actual place of the library, library assets, and librarianship. Administrators must be the first part to distinguish and comprehend the inadequacies and disadvantages of our calling. This target can be seen in Toghan's (Hafiz, 2006) saying: exaggeration isn't only a joke, be that as it may, it is [a] change and sanitisation [weapon]. The creators need to empower and animate more dialogue and discussion, advance basic reasoning, attract custodians' thoughtfulness regarding thoughts portrayed by personifications, and advertise librarianship as an appealing and significant calling, express a number or a repertoire of meanings at the same time because at this case they will be the type of artists who can affect or lead the masses towards their rights here.

Today, the media assume a viable part in improving the consciousness of individuals and their choice making. The more a subject is critical for individuals, the more

Media are focused on, and Pictures can influence crowds on their feelings and drive their view of news towards the objective. Among different pictures, exaggerations can be brought up, which are seen today in numerous daily papers, magazines and news locales nearby critical news (Soltanifar \& Bakhshi, 2010). Over the twentieth century, photographic, film, and televisual pictures have assumed an inexorably essential part in developing and documenting notable occasions. The appearance of broad communications has prompt a multiplication of pictures in non-inventive correspondence. In any case, pictures likewise have a focal impact on how creative discourse s conceptualise history; Mitchell has instituted the expression "pictorial turn" for this expanding "images" in contemporary correspondence, taking up Richard Rorty's contention that the historical backdrop of logic has advanced through a progression of worldview changes, or "turns": The photo of antiquated or medieval sense as worried about things, the rationality of the seventeenth through the nineteenth century as worried about thoughts, and the illuminated contemporary philosophical scene with words have extensive credibility. Hence, pictures are not just the world view in which modern culture must characterise its uncertain issues. However, they are adding the medium in which 
these issues are represented. One of the variables that helped Barack Obama win the fortyfourth presidential race was his solid media group. This article manages the part of pictorial discourse $s$ in media, concentrating on cartoons, in the forty-fourth presidential race of America.

\section{Cartoon in Jordan}

In March, Jordan's Ministry of Social Development issued amendments to Jordan's 2008 Law on Associations. The amendments place onerous restrictions on establishing civil society groups and grant the government legal authority to dissolve groups on vague grounds or deny their ability to obtain foreign funding without justification. If enacted, the changes would severely hamper the ability of NGOs to form and operate. By November, the amendments were still under consultation and had not been submitted to parliament.

Since the amended Public Gatherings Law took effect in March 2011, Jordanians no longer require government permission to hold public meetings or demonstrations. However, Amman hotels and other venues continued to seek permission to host public meetings and events. In April, authorities cancelled a concert by the famous Lebanese music group Mashrou'Leila, reportedly over the claim that their songs "contain lyrics that do not comply with the nature of the Jordanian society." The day before the concert was held, authorities reversed the decision, but organisers said they did not have time to stage it. The previous three decades in Jordan have conveyed to the cutting edge gendered morals of presence that looks to engrave a dream of womanliness that opposes the deterministic and abusive social parts forced by the prevailing male-centric mores and qualities. Emancipatory techniques have involved the notorious protection of social and political praxis. Yet, no maintained exertion has been applied to question the epistemological grounds of these unbending and naturalised abusive developments. In that capacity, I give a point-by-point diagram crafted by a conspicuous Jordanian illustrator/caricaturist, Imad Hajjaj, however, with specific accentuation on the portrayals of underestimated gatherings, principally ladies, that have risen in his work of late years. Remembering the unpredictability of his portrayals and the trouble of evaluating the different digressive practices reflected in his career, the paper might confine itself to the part such toons play in setting up and fortifying pictures, social images, commonplaces, tropes, what're more generalisations.

A progression of inquiries have been rationally postured while subjecting these Cartoons to the rigours of verbose analysis: 1 whose voice develops in these Cartoons? Do they specifically speak or mirror the hidden social practices, dialect amusements, and learning/control divisions of the society inside which they have tried to discover a crowd of people? What are the procedures of emblematic demolition, allegorical portrayals, iconoclasm, furthermore, dichotomising that underlie their creation? Is Imad Hajjaj the visual artist likewise, Imad Hajjaj is the craftsman as far as utilising the style and morals of the capable columnist to depoliticise the tasteful circle (Felski, 1989: 175)? I have contended somewhere else (Al-Mahadin, 2001) that the situation of ladies starts with the development of their subjectivity in discourse. The conclusive connection between information/control exhibited by Michel Foucault in a profoundly rooted vocation on the nexus amongst subjectivity and learning/control as uncovered by discourse suggests that such subjectivity be situated in the content and stood up to through movements in address. Political and social practices have occasioned the Cartoons under investigation yet the literary procedures utilised to duplicate and propagate the man-centric task of womanliness development through stereotyping. Establishing those Cartoons in a women's activist venture of desultory 
the examination ought to underscore the significance of deconstructing such renderings of womanliness if ladies' strengthening is ever to wind up an undeniable reality. In this way, "our comprehension of the issues of "genuine" ladies can't lie outside the "envisioned" builds in and through which "ladies" rise as subjects"(Rajeswari S. Rajan, 1994, p. 10). The situation of ladies in Jordan ought not to be limited to the standard techniques for altering laws and presenting enactments, yet additionally, be mixed with a women's liberation established in a conviction that "each portrayal depends on and duplicates a particular rationale of the genuine; this sensible, genuine advances its portrayal" (Peggy-Phelan, 1993, p. 10).

\section{Conclusion}

In conclusion, this study contributes to the body of knowledge by suggesting a model for a better understanding of Cartoons as a Social communicative tool in Jordan and specifically how Cartoons are used as social statements. Also, this study contributes to the media production industry in the Middle East and Jordan, mainly by providing a holistic framework that can help improve and develop the Quality of cartoon production. This study focuses on how the new cartoon and media communication between the new Jordan generations plays a vital role in highlighting the social cartoons in Jordan and popularising them to be used as an important way to criticise society in Jordan. In March, Jordan's Ministry of Social Development issued amendments to Jordan's 2008 Law on Associations. The amendments place onerous restrictions on establishing civil society groups and grant the government legal authority to dissolve groups on vague grounds or deny their ability to obtain foreign funding without justification. If enacted, the changes would severely hamper the ability of NGOs to form and operate. By November, the amendments were still under consultation and had not been submitted to parliament. Since the amended Public Gatherings Law took effect in March 2011, Jordanians no longer require government permission to hold public meetings or demonstrations. However, Amman hotels and other venues continued to seek permission to host public meetings and events. In April, authorities cancelled a concert by the famous Lebanese music group Mashrou' Leila, reportedly over the claim that their songs "contain lyrics that do not comply with the nature of the Jordanian society." The day before the concert was held, authorities reversed the decision, but organisers said they did not have time to stage it.

\section{Acknowledgement}

Thank you to the Institute of Postgraduate Studies (IPSis) UiTM for the financial support of this publication.

\section{References}

Brown, G., \& Yule, G. (1983). Discourse Analysis Cambridge: Cambridge University Press. Boeschoten, R. V. (2006). Media. Critical Perspectives on International Business 2(3): 220-229.

Christie, C. (2005). Editorial. Journal of Politeness Research 1 (1): 1-7.

Eggins, S. (2004). Introduction to systemic functional linguistics. A\&C Black.

Felski, R. (1989). Beyond feminist aesthetics: Feminist literature and social change. Harvard University Press.

Gill, S. K., \& Singh, S. (2015). A multimodal analysis of cover stories on mobile phones: An ideational perspective/Salveen Kaur Gill A/P Sakdev Singh (Doctoral dissertation, 
University of Malaya).

Gautier, D. (1985). The art of caricature. New York: Perigee Books.

Halliday, M. A. K. (2004). An introduction to functional grammar (3rd ed.), London: Edward Arnol

Halliday, M., \& Matthiessen, C. (2004). An introduction to functional grammar (3rd ed.). London: Arnold.

Hafiz, S. A. (2006). Caricature, the laughing tragedy: Content analysis of caricatures and cartoons published in Egyptian newspapers, namely Alakhbar-Alahram-AlwafdAlaraby Alosbou'-Sawt Aloma-Alahaly-Rose Alyossef magazine during the period from March 1st to December 31st 2005.

Jones, J. (2006). Multiliteracies for academic purposes : A metafunctional exploration of intersemiosis and multimodality in university textbook and computer-based learning resources in science.

Jewitt, C., \& Kress, G. (2003). A multimodal approach to research in education. Trentham Books in association with the Open University.

Kress, G., \& Van Leeuwen, T. (1996). 2006. Reading images: The grammar of visual design.

Kress, G. R., \& Van Leeuwen, T. (1996). Reading images: The grammar of visual design. Psychology Press.

Kaltenbacher, M. (2004). Perspectives on Multimodality: From the early beginnings to the state of the art. Information Design Journal \& Document Design, 12(3).

Kress, G., \& Van Leeuwen, T. V. (2001). Multimodal discourse: The modes and media of contemporary communication.

Lemke, J. L. (1998). Metamedia literacy: Transforming meanings and media. Handbook of literacy and technology: Transformations in a post-typographic world, 283-301.

Woniak, M. (2014) Mirror, Mirror on the Wall:Political Cartoons of the Arab Spring.

Martinec, R. (1998). Cohesion in action. Semiotica, 120(1), 161-180.

Management Communication, Department of Language and Business Communication Aarhus School of Business Aarhus University.

Meurer, J. L., \& Machado, F. R. (2010). Context, genre and multimodality: An analysis of an on-line news article. Nonada Letras em Revista, 12(12), 71-84.

Nugroho, A. D. (2009). The generic structure of print advertisement of Elizabeth Arden's INTERVENE: A multimodal discourse analysis. k@ ta, 11(1), 70-84.

O'Halloran, K. (2008). Mathematical discourse: Language, symbolism and visual images. A\&C Black.

O'toole, M. (1994). The language of displayed art. Fairleigh Dickinson Univ Press. O'Halloran, K. L. (2008). Systemic functional-multimodal discourse analysis (SFMDA): constructing ideational meaning using language and visual imagery. Visual Communication (Vol. 7, pp. 443-475).

O’Halloran, K. L. (2005) Mathematical Discourse: Language, Symbolism and Visual Images. London: Continuum.

Phelan, P. (1993). The ontology of performance: representation without reproduction.

Ramachandran, V. S., \& Hirstein, W. (1999), The science of art: A neurological theory of aesthetic experience. Journal of Consciousness Studies 6: 15-51.

Redman, L. (1984). How to draw caricatures. Chicago: Contemporary Books.

Al-Mahadin, S. (2003). Gender representations and stereotypes in cartoons: a Jordanian case study. Feminist Media Studies, 3(2), 131-151.

Rajan, R. S. (1994). Imagined Women: Women, Gender, Culture and Postcolonialism. 
Rhodes, G., \& McLean, I. A. (1990). Distinctiveness and expertise effects with homogeneous stimuli: Towards a model of configural coding. Perception 19: 773-794.

Stock, C. (2008). George w. bush caricatures.

Stubbs, M. (1983). Discourse analysis: The sociolinguistics analysis of national language. OxfordBasil: Blackwell.

Sorensen, L. (2011). A Multimodal approach for advertising for professionals in the film, television and photography business. Retrieved from Department of Language and Business Communication Aarhus School of Business Aarhus University.

Siegel, M. (2006). Rereading the signs: Multimodal transformations in the field of literacy education. Language Arts, 84(1), 65-77.

Siegel, M., \& Panofsky, C. P. (2009). Designs for multimodality in literacy studies: Explorations in analysis. In 58th yearbook of the national reading conference (pp. 99-111). Oak Creek, WI: National Reading Conference, Inc.

Soltanifar, M., \& Bakhshi, B. (2010). The Role of Pictorial Discourses in the Forty-Fourth Presidential Election of America.

Shafiq, Q., Hameed, M. B., \& Zafar, M. A. (2017). DISCURSIVE (RE) CONSTRUCTION OF SOUTH ASIAN POLITICS: A STUDY Of CARICATURES. European Journal of Research in Social Sciences Vol, 5(1).

Van Dijk, T. A. (1993a). Principles of Critical Discourse Analysis: Discourse in society.

Al-Homoudi, I. A., Thakur, J. S., Naik, R., Auner, G. W., \& Newaz, G. (2007). Anatase TiO2 films based $\mathrm{CO}$ gas sensor: Film thickness, substrate and temperature effects. Applied Surface Science, 253(21), 8607-8614.

Alessandri, I., Comini, E., Bontempi, E., Faglia, G., Depero, L. E., \& Sberveglieri, G. (2007). $\mathrm{Cr}$-inserted $\mathrm{TiO} 2$ thin films for chemical gas sensors. Sensors and Actuators B: Chemical, 128(1), 312-319.

Alterkop, B., Parkansky, A. N., Goldsmith, A. S., \& Boxman, A. R. L. (2003). Effect of air annealing on opto-electrical properties of amorphous tin oxide films. Journal of Physics D: Applied Physics, 36, 552.

Ang, G. T., Toh, G. H., Bakar, M. Z. A., Abdullah, A. Z., \& Othman, M. R. (2011). High sensitivity and fast response $\mathrm{SnO} 2$ and $\mathrm{La}-\mathrm{SnO} 2$ catalytic pellet sensors in detecting volatile organic compounds. Process Safety and Environmental Protection, 89(3), 186-192.

Balasubramanian, G., Dionysiou, D. D., Suidan, M. T., Baudin, I., \& Laine, J.-M. (2004). Evaluating the activities of immobilised $\mathrm{TiO}_{2}$ powder films for the photocatalytic degradation of organic contaminants in water. Applied Catalysis B: Environmental, 47(2), 73-84.

Chen, W., Zhang, J., Fang, Q., Li, S., Wu, J., Li, F., \& Jiang, K. (2004). Sol-gel preparation of thick titania coatings aided by organic binder materials. Sensors and Actuators B: Chemical, 100(1-2), 195-199.

Chen, Y., \& Dionysiou, D. D. (2006). TiO2 photocatalytic films on stainless steel: The role of Degussa P-25 in modified sol-gel methods. Applied Catalysis B: Environmental, 62(3-4), 255-264.

Garzella, C., Comini, E., Tempesti, E., Frigeri, C., \& Sberveglieri, G. (2000). TiO2 thin films by a novel sol-gel processing for gas sensor applications. Sensors and Actuators B: Chemical, 68(1-3), 189-196.

Kermanpur, A., Ghassemali, E., \& Salemizadeh, S. (2008). Synthesis and characterisation of microporous titania membranes by dip-coating of anodised alumina substrates using sol-gel method. Journal of Alloys and Compounds, 461(1-2), 331-335. 
Mohammadi, M. R., \& Fray, D. J. (2007). Semiconductor TiO2-Ga2O3 thin film gas sensors derived from particulate sol-gel route. Acta Materialia, 55(13), 4455-4466.

Ruiz, A. M., Cornet, A., \& Morante, J. R. (2004). Study of La and Cu influence on the growth inhibition and phase transformation of nano-TiO2 used for gas sensors. Sensors and Actuators B: Chemical, 100(1-2), 256-260.

Ruiz, A. M., Sakai, G., Cornet, A., Shimanoe, K., Morante, J. R., \& Yamazoe, N. (2004). Microstructure control of thermally stable TiO2 obtained by hydrothermal process for gas sensors. Sensors and Actuators B: Chemical, 103(1-2), 312-317.

Senguttuvan, T. D., Rai, R., \& Lakshmikumar, S. T. (2007). Gas sensing properties of lead doped tin oxide thick films. Materials Letters, 61(2), 582-584.

Takahashi, Y., \& Matsuoka, Y. (1988). Dip-coating of TiO2 films using a sol derived from $\mathrm{Ti}(\mathrm{O}-\mathrm{i}-\mathrm{Pr}) 4-$ diethanolamine-H2O-i-PrOH system. Journal of Materials Science, 23(6), 2259- 2266.

Taurino, A. M., Capone, S., Boschetti, A., Toccoli, T., Verucchi, R., Pallaoro, A., lannotta, S. (2004). Titanium dioxide thin films prepared by seeded supersonic beams for gas sensing applications. Sensors and Actuators B: Chemical, 100(1-2), 177-184.

Yang, T., Lin, H., Wei, B., Wu, C., \& Lin, C. (2003). UV enhancement of the gas sensing properties of nano-TiO2. Rev. Adv. Mater. Sci, 4, 48-54.

Zhang, X., Zhou, M., \& Lei, L. (2005). Preparation of anatase TiO2 supported on alumina by different metal organic chemical vapor deposition methods. Applied Catalysis A: General, 282(1-2), 285-293. 